Journal of Neurology, Neurosurgery, and Psychiatry 1984;47:91-93

Short report

\title{
Visual, cortical somatosensory and brainstem auditory evoked potentials following incidental irradiation of the rhombencephalon
}

\author{
S NIGHTINGALE, IS SCHOFIELD, PJDK DAWES
}

From the Department of Neurology, Royal Victoria Infirmary, the Department of Clinical Neurophysiology, Regional Neurological Centre, Newcastle General Hospital, and the Regional Radiotherapy Centre, Newcastle General Hospital, Newcastle upon Tyne, UK

SUMMARY Visual, cortical somatosensory and brainstem auditory evoked potentials were recorded before incidental irradiation of the rhombencephalon and at 11 weeks and eight months after completion of treatment. No patient experienced neurological symptoms during this period. No consistent changes in evoked potentials were found. The failure to demonstrate subclinical radiation-induced demyelination suggests either that the syndrome of early-delayed radiation rhombencephalopathy occurs in an idiosyncratic manner, or that any subclinical lesions are not detectable by serial evoked potential recordings.

The syndrome of early-delayed radiation rhombencephalopathy has been reported in five patients. ${ }^{1-3}$ Each received maximal tumour doses of about 5500 rads to tumours in or around the middle ear. In four patients, the dose fractionation and field parameters were similar and a comparable dose of radiation was delivered to the rhombencephalon: in the other patient the fractionation and field parameters were not specified. The clinical features started two to three months after completion of radiotherapy and consisted of nausea, vomiting, ataxia, dysarthria, cranial nerve palsies, internuclear opthalmoplegia and signs of corticospinal tract involvement. Three patients made a complete or partial recovery but two died within a month of onset of the illness. The necropsy ${ }^{24}$ of these patients revealed plaques of demyelination similar to those found in multiple sclerosis but limited to the volume of brainstem irradiated.

A demyelinating pathogenesis for early-delayed

\footnotetext{
Address for reprint requests: Dr S Nightingale, Department of Neurology, Queen Elizabeth Hospital, Queen Elizabeth Medical Centre, Edgbaston, Birmingham B15 2TH, UK
}

Received 6 May 1982 and in final revised form 3 May 1983. Accepted 28 June 1983 radiation rhombencephalopathy is suggested by the necropsy findings and by the particular sensitivity of oligodendrocytes to radiation. ${ }^{5}$ The delay between radiation and the onset of the rhombencephalopathy accords well with the myelin turnover time of between five weeks and two months. ${ }^{6}$ The similarity of the clinical features of early-delayed radiation rhombencephalopathy to those of multiple sclerosis also is suggestive of a demyelinating pathogenesis.

Evoked potential studies have demonstrated both overt and subclinical demyelination in multiple sclerosis $^{7}$ and similar findings might be expected following radiation-induced demyelination. We have therefore studied the visual, cortical somatosensory and brainstem auditory evoked potentials (VEP, SEP and BAEP respectively) in five patients who had received incidental radiation to their nervous system in similar doses to the reported cases of early-delayed radiation rhombencephalopathy.

\section{Patients and methods}

Five patients were studied (table 1). The tumours were irradiated by anterior-oblique and posterior-oblique fields using Cobalt-60 gamma radiation with beam trimmers (Patients 2, 4, 5) or 4MV XRs (Patients 1,3). The isodose treatment plan of Patients 1,2 and 3 were similar to the 
Table 1 Patients and radiation details

\begin{tabular}{|c|c|c|c|c|c|c|c|c|}
\hline Patient & Sex & Age (yr) & Tumour & $\begin{array}{l}\text { Fraction } \\
\text { Dose (rads) }\end{array}$ & $\begin{array}{l}\text { Fraction } \\
\text { Number }\end{array}$ & $\begin{array}{l}\text { Duration of } \\
\text { treaiment (days) }\end{array}$ & TDF Number & $\begin{array}{l}\text { Mean dose to } \\
\text { brainstem (rads) }\end{array}$ \\
\hline $\begin{array}{l}1 \\
2 \\
3 \\
4 \\
5\end{array}$ & $\begin{array}{l}\mathbf{F} \\
\mathbf{F} \\
\mathbf{M} \\
\mathbf{M}\end{array}$ & $\begin{array}{l}61 \\
69 \\
54 \\
68 \\
68\end{array}$ & $\begin{array}{l}\text { Glomus jugulare } \\
\text { Glomus jugulare } \\
\text { Glomus jugulare } \\
\text { Middle ear carcinoma } \\
\text { Parotid adenocarcinoma }\end{array}$ & $\begin{array}{l}200 \\
200 \\
200 \\
400 \\
300\end{array}$ & $\begin{array}{l}25 \\
25 \\
25 \\
10 \\
15\end{array}$ & $\begin{array}{l}35 \\
35 \\
35 \\
24 \\
22\end{array}$ & $\begin{array}{l}82 \\
82 \\
82 \\
88 \\
92\end{array}$ & $\begin{array}{l}2429 \\
2222 \\
2350 \\
2044 \\
1850\end{array}$ \\
\hline
\end{tabular}

illustrated plan in reference 3 . The mean brainstem dose and the time-dose-fractionation number have been calculated for each patient. ${ }^{8}$

Evoked potentials were recorded before radiotherapy and at 11 weeks and eight months after completion of radiotherapy. Patient 4 developed a bronchial carcinoma and was unable to attend for the eight month evoked potential recording. In Patients 1,4 and 5 , the BAEP ipsilateral to the tumour could not be recorded before radiotherapy owing to inflammation of the external auditory meatus. The patients were interviewed and examined each time that they attended for evoked potential recordings.

The evoked potentials were recorded by the methods of Halliday et al, ${ }^{9}$ Cracco et $a l^{10}$ and Starr et al. ${ }^{11}$ Visual evoked potentials (VEPs) were generated by 128 pattern reversals of a $40^{\prime}$ checks to each eye and recorded from an electrode $5 \mathrm{~cm}$ above the inion with a frontal reference (Fz). Sensory evoked potentials (SEPs) were generated by 256 electrical stimulations of the median nerve at each wrist at the motor response threshold: they were recorded from electrodes on the scalp seven centimetres lateral to the midline over the contralateral somatosensory cortex (1 $\mathrm{cm}$ anterior to $\mathrm{P} 3, \mathrm{P} 4)$ with a frontal reference $(\mathrm{Fz})$. Brainstem auditory evoked potentials (BAEPs) were generated by 1024 high intensity clicks at $70 \mathrm{db}$ above the sensory threshold and recorded from electrodes over the ipsilateral mastoid process $(A 1, A 2)$ referred to the vertex.

\section{Results}

None of the patients had symptoms or signs of early-delayed radiation rhombencephalopathy. There were no consistent changes in the serial recordings of the VEP, SEP or BAEP (table 2). In Patient 4, the VEP from each eye had grossly abnormal patterns and the P100 could not be identified; however the patterns were unchanged at 11 weeks. $\mathrm{F}$ tests and paired $t$ tests between the measurements performed before radiation and at 11 weeks and at eight months showed no significance at the $95 \%$ level.

\section{Discussion}

The five patients studied experienced no neurological symptoms in the early-delayed period and showed no serial changes in VEP, SEP or BAEP. This indicates either that the incidental radiation did not cause subclinical demyelination or that any such demyelination is not demonstrable by these methods. The syndrome of early-delayed radiation rhombencephalopathy may occur in an idiosyncratic rather than dose-related manner: it is rare $^{3}$ and the

Table 2 Latency of evoked potentials (milliseconds) from recordings before treatment (a), and eleven weeks (b) and eight months (c) following completion of treatment. For each patient the upper and lower rows refer to the evoked potentials ipsilateral and contralateral to the tumour respectively

\begin{tabular}{|c|c|c|c|c|c|c|c|c|c|}
\hline \multirow{2}{*}{$\begin{array}{l}\text { Patient } \\
\text { Number }\end{array}$} & \multicolumn{3}{|l|}{$V E P$} & \multicolumn{3}{|l|}{$S E P$} & \multicolumn{3}{|l|}{$B A E P$} \\
\hline & $\begin{array}{l}P 100 \\
a\end{array}$ & $\begin{array}{l}P 100 \\
b\end{array}$ & $\begin{array}{l}P 100 \\
c\end{array}$ & $\begin{array}{l}N_{20} \\
a^{2}\end{array}$ & $\underset{b}{N_{20}}$ & $\begin{array}{l}N_{20} \\
c^{2}\end{array}$ & $\begin{array}{l}N_{1}-N_{5} \\
a\end{array}$ & $\underset{b}{N_{1}-N_{5}}$ & $\begin{array}{l}N_{1}-N_{5} \\
c\end{array}$ \\
\hline 1 & 101 & 100 & 106 & $19 \cdot 4$ & $21 \cdot 2$ & $20 \cdot 2$ & NR & $2 \cdot 8$ & $3 \cdot 3$ \\
\hline & 102 & 101 & 104 & $21 \cdot 4$ & 20.9 & 19.4 & $2 \cdot 9$ & $2 \cdot 8$ & $3 \cdot 3$ \\
\hline 2 & 100 & 95 & 96 & $18 \cdot 0$ & $21 \cdot 2$ & $18 \cdot 3$ & $3 \cdot 0$ & $2 \cdot 9$ & $3 \cdot 3$ \\
\hline & 98 & 101 & 98 & $18 \cdot 3$ & $20 \cdot 5$ & $18 \cdot 1$ & $3 \cdot 1$ & $3 \cdot 1$ & $3 \cdot 1$ \\
\hline & 95 & 93 & 96 & $18 \cdot 6$ & $20 \cdot 1$ & $21 \cdot 6$ & $2 \cdot 9$ & $3 \cdot 0$ & $3 \cdot 1$ \\
\hline 4 & - & - & NR & $21 \cdot 9$ & $21 \cdot 7$ & NR & NR & $3 \cdot 2$ & NR \\
\hline & - & - & NR & $21 \cdot 2$ & 19.6 & NR & $2 \cdot 9$ & 2.9 & NR \\
\hline 5 & 134 & 130 & 128 & $21 \cdot 1$ & $20 \cdot 5$ & $21 \cdot 5$ & NR & $3 \cdot 2$ & $3 \cdot 0$ \\
\hline & 122 & 124 & 124 & $21 \cdot 2$ & 19.5 & $20 \cdot 2$ & $3 \cdot 1$ & $3 \cdot 1$ & $3 \cdot 0$ \\
\hline $\mathbf{N}$ & 8 & 8 & 8 & 10 & 10 & 8 & & 10 & 8 \\
\hline Mean & $106 \cdot 13$ & 105 & 106 & $20 \cdot 1$ & 20.5 & 19.9 & 2.97 & $3 \cdot 0$ & $3 \cdot 15$ \\
\hline${ }^{0} \mathrm{~N}-1$ & 14.05 & 13.98 & 12.96 & 1.44 & 0.75 & $1 \cdot 30$ & 0.095 & $0 \cdot 15$ & 0.13 \\
\hline
\end{tabular}

(NR = evoked potentials not recorded) 
susceptibility of just a few patients to radiationinduced demyelination may be due to an inherited diathesis or a concomitant acquired subclinical central nervous system disorder, such as multiple sclerosis or paraneoplastic neurotoxicity.

Evoked potential studies of the effects of rhombencephalic irradiation have not been previously reported. However, SEPs have been recorded following incidental spinal cord irradiation in man in order to study the rare syndrome of transient radiation myelopathy ${ }^{12}$ and to detect subclinical radiation damage. ${ }^{13}$ The syndrome of transient radiation myelopathy consists of dysaesthesiae and Lhermitte's phenomenon following incidental spinal cord irradiation. It occurs during the early-delayed period and, like early-delayed radiation rhombencephalopathy, its clinical features resemble those of multiple sclerosis. It has been suggested that this early-delayed radiation myelopathy is also due to radiation-induced myelin damage, though there are no histological reports of necropsies performed during or soon after the onset of this syndrome. Lecky et $a^{12}$ studied six patients before, immediately after and six months after incidental spinal cord irradiation. Although two patients had transient symptoms of early-delayed radiation myelopathy, none had abnormal neurological signs and the SEPs were unchanged. Lecky $e t$ al ${ }^{12}$ suggest that the putative demyelinating lesions in these patients may affect only a short segment of the spinal cord and therefore any slowing of conduction may not be detectable. The same may be true in the case of early-delayed radiation rhombencephalopathy. Dorfman et al ${ }^{13}$ found delayed SEPs in 15 patients following spinal cord irradiation compared to 15 age-matched normal controls. This effect was not proportional to the radiation dose but was inversely related to both treatment time and number of fractions. However, in contrast to our study and to that of Lecky et al, ${ }^{12}$ evoked potentials were not recorded before radiotherapy: the apparent slowing of conduction in the irradiated patients compared to the controls may have been due to a neurotoxic effect of cancer, rather than an effect of the radiation itself.

We have failed to demonstrate subclinical CNS damage during the early-delayed period in patients receiving a brainstem radiation dose similar to the reported cases of early-delayed radiation rhombencephalopathy. Either the demyelination lesions of early-delayed radiation rhombencephalopathy only occur in patients with a pre-existing susceptibility or, as in the case of early-delayed radiation myelopathy ${ }^{12}$ the lesions are not detectable by serial recordings of evoked potentials.
We thank Miss BP Longley, OBE and her staff for performing the evoked potential studies and Drs DD Barwick and NEF Cartlidge for their advice and encouragement. The equipment used for the evoked potentials was provided through a grant from the Multiple Sclerosis Society.

\section{References}

' Rider WD. Radiation damage to the brain-a new syndrome. J Can Assoc Radiol 1963;14:67-9.

${ }^{2}$ Lampert PW, Davis RL. Delayed effects of radiation on the human nervous system. "Early" and "late" delayed reactions. Neurology (Minneap) 1964;14:912-7.

${ }^{3}$ Nightingale S, Dawes PJDK, Cartlidge NEF. Earlydelayed radiation rhombencephalopathy. J Neurol Neurosurg Psychiatry 1982;45:267-70.

${ }^{4}$ Lampert P, Tom MI, Rider WD. Disseminated demyelination of the brain following $\mathrm{Co}^{60}$ (Gamma) radiation. Arch Pathol 1959;68:322-30.

${ }^{s}$ Zeman W, Samorajski T. Effects of radiation on the nervous system. In: Berdjis CC, ed. Pathology of Irradiation. Baltimore, Maryland: Williams and Wilkins, 1971:213-77.

' Norton WT, Myelin. In: Albert RW, Siegel GJ, Katzman $\mathrm{R}$, et al, eds. Basic Neurochemistry. Boston: Little, Brown and Company, 1972:365-84.

${ }^{7}$ Deltenre P, Van Nechel C, Vercruysse A, Strul S, Capon A, Ketelaer P. Results of a prospective study of combined visual, somatosensory, brainstem auditory evoked potentials and blink reflex measurements for disclosing subclinical lesions in suspected multiple sclerosis. In: Courjon J, Mauguiere F, Revol M, eds. Clinical Applications of Evoked Potentials in Neurology. New York: Raven Press, 1982:473-9.

${ }^{8}$ Orton CG, Ellis F. A simplification in the use of the NSD concept in practical radiotherapy. $\mathrm{Br} J$ Radiol 1973;46:529-37.

9 Halliday AM, Barrett G, Halliday E, Michael WF. The topography of the pattern evoked potential. In: Desmedt JE, ed. Evoked Potentials in Man: New Developments 1977:121-33.

${ }^{10}$ Cracco RQ, Cracco JB. Somatosensory evoked potentials in man: far field potentials. Electroencephalogr Clin Neurophysiol 1976;41:460-6.

"Starr A, Achor LJ. Auditory brainstem responses in neurological disease. Arch Neurol 1975;32:761-8.

12 Lecky BRF, Murray NMF, Berry RJ. Transient radiation myelopathy: spinal somatosensory evoked responses following incidental cord exposure during radiotherapy. J Neurol Neurosurg Psychiatry 1980;43:747-50.

${ }^{13}$ Dorfman LJ, Donaldson SS, Gupta PR, Bosley TM. Subclinical radiation myelopathy in humans. Neurology (Minneap) 1981;31:67. 